\title{
Thinker's Sign
}

\author{
Sandeep M. Patel ${ }^{1}$, Jay H. Ryu ${ }^{2}$ and Hiroshi Sekiguchi ${ }^{2}$
}

Key words: Thinker's Sign, Chronic Obstructive Pulmonary Disease (COPD)

(Intern Med 50: 2867-2868, 2011)

(DOI: 10.2169/internalmedicine.50.6314)

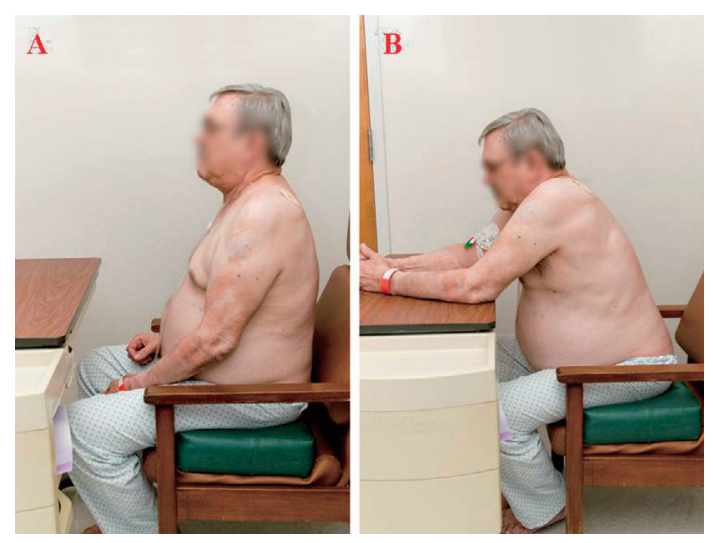

Picture 1.

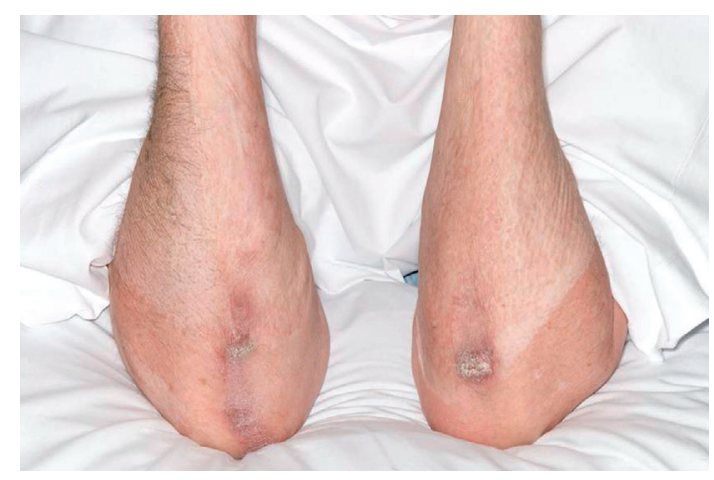

Picture 2.

mon skin manifestations associated with severe COPD, fol-

A 65-year-old man was admitted for a COPD exacerbation. Physical examination was notable for a dyspneic, barrel-chested, Caucasian man leaning forward on a table (Picture 1). Lung auscultation revealed bilateral wheezes with a prolonged expiratory phase. Dermatologic examination demonstrated hyperpigmentation and hyperkeratosis of both elbows that was non-tender and cool to palpation (Picture 2).

Thinker's sign [also known as Dahl's sign (1)] was first described in a patient with severe COPD in 1963 (2). Classically, the sign is seen on the thighs of the patients who spend a majority of their time in the "tripod" position with their elbows resting on the front third of their thigh (2). Repeated and constant pressure on the epidermis leads to a characteristic reaction of hyperpigmentation and hyperkeratosis, i.e. callus. This callus formation may also be present on patient's elbows, as in the present patient, when patients are more accustomed to leaning forward on flat surfaces, furniture, or other means of support. This was first reported in 1985 in a patient with severe COPD and termed "hyperkeratoses of forearms associated with pulmonary disease (3)." Subsequently, a case series in 1991 reported that the hyperkeratosis of forearms and/or thighs was the second most com-

lowed by nail changes (4). Since these initial reports, the Thinker's sign has also been colloquially referred to as "prayer marks" and has been witnessed in the Muslim population as a potential sign of worsening symptoms in obstructive pulmonary disease (5).

The characteristic "tripod" or "leaning forward" posture is assumed to optimize inspiratory accessory muscle effort and allows the diaphragm to regain its natural shape and pistonlike motion to help improve inspiration (6). It has been noted to be observed in severe COPD (FEV1 $<30 \%$ predicted), but can also be seen in other conditions notable for respiratory distress, including congestive heart failure or intersitial lung disease (7). He was treated appropriately, and his follow-up pulmonary function testing confirmed severe obstruction with evidence of air trapping and decreased diffusing capacity.

The authors state that they have no Conflict of Interest (COI).

\section{References}

1. Dahl MV. Emphysema. Arch Dermatol 101: 117, 1970.

2. Rothenberg HJ. The thinker's sign. JAMA: J Am Med Assoc 184:

${ }^{1}$ Department of Internal Medicine, Mayo Clinic, USA and ${ }^{2}$ Division of Pulmonary and Critical Care Medicine, Mayo Clinic, USA Received for publication August 6, 2011; Accepted for publication August 24, 2011

Correspondence to Dr. Hiroshi Sekiguchi, sekiguchi.hiroshi@mayo.edu 
902-903, 1963.

3. Kaufman WH, Kaufman JP. Hyperkeratoses of forearms associated with chronic lung disease. J Am Acad Dermatol 13: 681-682, 1985.

4. Pride H. The dermatology of chronic lung disease. Cutis 48: 398403, 1991.
5. Cangiano M, Chisti MJ, Pietroni MA, Smith JH. Extending prayer marks as a sign of worsening chronic disease. J Health Popul Nutr 29: 290-291, 2011.

6. Lemyze M, Van Grunderbeeck N, Mallat J, Thevenin D. Thinker's Sign. Am J Respir Crit Care Med 183: 413, 2011.

7. Rebick G, Morin S. The thinker's sign. CMAJ 179: 611, 2008.

(C) 2011 The Japanese Society of Internal Medicine http://www.naika.or.jp/imindex.html 